\title{
REPRESENTACÕES FEMININAS E O PÓS- COLONIALISMO EM DIZES-ME COISAS AMARGAS COMO FRUTOS, DE ANA PAULA TAVARES
}

\author{
Maria do Socorro Baptista Barbosa (UFSC) \\ Francisco Brunno Carvalho Reis (UESPI)
}

Resumo: Este trabalho investiga as características do pós-colonialismo e a representação da mulher na poesia de Ana Paula Tavares, poetisa que define, em sua escrita, o processo colonial de Angola, descrevendo a angústia, o sofrimento e as dores de seu povo, subjugado pelo poder opressor. Utilizou-se como referencial teórico Bhabha (1980), Beauvoir (1970), dentre outros. Como resultado da pesquisa, observou-se que a poetisa aborda a temática colonial, retratando o processo de dominação por parte das potências imperialistas e como a colonização afetou os povos angolanos, estes sofrendo perdas cujos resquícios perduram até a pós-modernidade.

Palavras-Chave: Colonial; Mulher; Dominação; Pós-modernidade.

Abstract: This work investigates the characteristics of the postcolonialism and the woman representation in the poetry written by Ana Paula Tavares, poetess who defines, in her writing, the colonial process of Angola, describing the anguish, the suffering and the pain of her people subjugated by the oppressor power. It was used as theoretical reference Bhabha (1980), Beauvoir (1970), among others. As result of the research, it was observed that the poetess has approached the colonial thematic, portraying the domination process occurred by imperialist powerful countries and how the colonization affected the Angolan people, these who are suffering losings whose traces have continued until the post-modernity.

Keywords: Colonial; Woman; Domination; Post-modernity.

\section{INTRODUÇÃO}

A literatura africana de língua portuguesa tem como objetivos a busca por sua identidade nacional, o resgate da 
tradição dos povos africanos e, mais especificamente, dos angolanos. Ela aborda os principais temas que versam sobre o processo de imposição cultural aos povos colonizados, bem como sobre o modo de vida deles.

A respeito do processo de imposição cultural, "reconstituir o discurso das diferenças culturais exige não apenas uma mudança de conteúdo e símbolos culturais, mas uma substituição dentro da mesma moldura temporal de representação nunca adequada" (BHABHA, 1990, p.240). A literatura africana e os estudos culturais pautam-se na revisão da representação dos personagens da história africana, com o intuito de valorizar sua história e cultura e obter uma nova perspectiva em relação à forma como os povos africanos são vistos pelo colonizador.

Os estudos culturais investigam a dialética entre colonizador e colonizado na pós-modernidade, uma vez que existe um jogo dos interesses entre esses dois grupos, pois, enquanto este objetiva autoafirmar-se, aquele luta para preservar seu poder perante os povos recém-independentes.

Quanto aos estudos pós-coloniais, García e Mata (2016, p.178) comentam que:

Assim, os estudos pós-coloniais, mais do que uma disciplina ou ciência, é um campo abrangente de reflexão por onde a crítica 
transita e que tem por valor principal a construção de um olhar crítico, senão desprovido dos modelos tradicionais de investigação, mas problematizador de si mesmo, ao colocar em suspenso os seus próprios métodos investigativos.

As pesquisas referentes ao pós-colonialismo têm como função questionar o que a literatura canônica enuncia em relação às civilizações dominadas, uma vez que o discurso dessa literatura é pautado no papel doutrinário do homem branco, culto e civilizado, em oposição à vida e cultura das populações africanas (GARCÍA; MATA, 2016).

Um dos assuntos tratados pela literatura que nasce na pós-modernidade é a questão da mulher que é colonizada. Além de viver dominada em relação ao homem, ela ainda convive com os dilemas do processo civilizatório das grandes potências imperialistas, o que se configura como uma dupla subalternidade praticada contra a figura feminina, pois, não obstante, viver em um país com valores tradicionais, dentre os quais a dominação masculina impera, sofre, ainda, com os mandos dos padrões europeus.

Dessa forma, por meio da poesia e do seu jogo com imagens, este trabalho busca abordar os processos coloniais e a representação da mulher em um contexto marcado pela hegemonia das potências imperialistas, no que diz respeito à 
preservação de seus valores e privilégios históricos.

\section{A HERANÇA CULTURAL: A ORIGEM DA ORALIDADE}

A literatura africana de língua portuguesa, sobretudo a angolana, faz-se presente na medida em que comenta a história de vida de seu povo, com suas perdas e sofrimentos provocados pelo processo civilizatório.

Herdeira de um passado dominador, em que culturas africanas foram subjugadas, tal literatura reflete, por meio da sua escrita, a identidade angolana. Sobre esse assunto, afirma Bhabha (1998, p.241):

A cultura se adianta para criar uma textualidade simbólica, para dar ao cotidiano alienante uma aura de individualidade, uma promessa de prazer. A transmissão de culturas de sobrevivência não ocorre no organizado musée imaginaire das culturas nacionais com seus apelos pela continuidade de um "passado" autêntico e um "presente" vivo - seja essa escala de valor preservada nas tradições "nacionais" organicistas do romantismo ou dentro das proporções mais universais do classicismo. A cultura como estratégia de sobrevivência é tanto transnacional como tradutória, ela é transnacional porque os discursos pós-coloniais contemporâneos estão enraizados em histórias específicas de deslocamento cultural, seja como "meiapassagem" da escravidão e servidão, 
como "viagem para fora" da missão civilizatória, a acomodação maciça da migração do Terceiro Mundo para - Ocidente após a Segunda Guerra Mundial, ou o trânsito de refugiados econômicos e políticos dentro e fora do Terceiro Mundo.

A escrita de África pós-colonial é pautada na sede das novas entidades que emergem e estão a emergir no cenário pós-moderno. Isso porque as culturas colonizadas foram, por muito tempo, deixadas de lado por toda a literatura, uma vez que só era vista a literatura canônica, dos assuntos e interesses das potências. O acervo cultural identitário, isto é, aspectos que dizem respeito ao modo de vida desses povos dominados, bem como da sua história e tradição, passam, agora, a serem reescritos e, dessa forma, revelados ao mundo dos quais fazem parte.

É justamente disso que trata a poesia de Ana Paula Tavares (2001, p.21), mais especificamente, do livro Dizesme coisas amargas como frutos, no qual se pode encontrar este poema:

CAOS

CACTUS

CACOS

mãos feridas d'espinhos

pousadas pássaros

no meu rosto.

(...) 
Percebe-se que a voz que fala no poema retrata um cenário em que a morte está presente, uma vez que se trata da vegetação que fere e altera a estrutura do tecido epitelial do sujeito, cuja consequência é o estado deprimente no qual se encontra o eu-lírico. O que permite dizer que o mesmo foi maltratado e ferido, por algo que quer lhe derrubar ou afetar.

A oralidade, por exemplo, se materializa nesses aspectos que condizem com a forma como os povos africanos se comunicavam nas situações distendidas do cotidiano, sem, contudo, utilizar a linguagem escrita. A comunicação se pautava na forma como as populações de África falavam e se expressavam, como por exemplo, pela voz e pelos gestos faciais.

Dessa forma, a linguagem falada é a marca característica da identidade do povo angolano, pois, por pertencer a uma comunidade tipicamente arcaica, o padrão escrito não era cultivado pelo povo dessa região, o que faz com que a comunicação seja realizada pelo registro falado.

Assim, discorre Leite (2014, p.17):

A predominância da oralidade em África é resultante de condições materiais e históricas e não uma resultante da "natureza" africana; mas muitas vezes esse facto é confusamente analisado, e 
muitos críticos partem do princípio de que há algo ontologicamente oral em África e que a escrita é um acontecimento disjuntivo e alienígeno para os africanos.

A sociedade africana era antiga e preservava traços de uma tradição milenar, não só na forma de interação entre os membros, mas na própria divisão entre seus grupos. Ou seja, além de não reconhecerem a escrita, as comunidades angolanas obedeciam, rigorosamente, as estruturas estamentárias de divisão social e sexual.

Diante do exposto, por preservarem seus papéis, rigidamente hierarquizados na sociedade angolana, as mulheres eram relegadas às funções domésticas, como cuidar de casa, preparar o alimento para os maridos, dentre outras atividades, porém, sempre seu talento ficou à mercê, pois não se tinha espaço para desenvolvê-lo, devido às condições às quais eram expostas.

\section{A MULHER E SEU PAPEL NA COMUNIDADE ANGOLANA: UMA REFLEXÃO}

A figura feminina na sociedade era subalterna, ou seja, a mulher se encontrava em um patamar inferior aos homens, uma vez que estes representavam os lugares públicos, isto é, de maior visibilidade, consoante a isso, eles se mantinham no comando das sociedades angolanas. 
A respeito do feminismo colonial, García e Mata (2016, p.182) afirmam que:

As identidades de gênero, ao lado das identidades nacionais, formularam os aspectos mais radicais das identidades na modernidade, na medida em que deram suporte às subjetivações dos indivíduos, que transitavam irremediavelmente da cultura do Antigo Regime para a modernidade. Foi nesse sentido que os estudos sobre as mulheres e o feminismo deram uma contribuição inquestionável para o reconhecimento da instabilidade da formação das identidades de gênero e da cultura da modernidade.

A questão da inserção dos novos padrões femininos a serem exercidos pela mulher angolana será abordada como forma de questionar como as figuras femininas eram até então representadas, isto é, elas sempre foram retratadas sob o jugo do poder dominante, como também das potências imperialistas. A revisão das obras canônicas escritas se pauta na nova configuração da mulher nessas obras, porque, na pós-modernidade, surge a mulher escritora, que pode representar e descrever a situação da mulher do seu tempo.

A representação feminina, subalterna e alienada perante o poder opressor masculino, bem como perante o poder colonial, sofre alteração, passando a ser vista como quem, agora, luta para conduzir seu próprio destino e/ou não 
admite os papéis que Ihes são impostos. Surge, assim, uma nova teoria que condiz com esses novos paradigmas da sociedade angolana (GARCÍA; MATA, 2016).

Um exemplo disso pode ser encontrado na poesia de Ana Paula Tavares (2001, p.34), no poema As Viúvas:

No entanto

Kalunga, oh Kalunga,

Como estou necessitada

Como preciso de sorte...

(...)

Percebe-se que a mulher do poema é caracterizada pela agonia, desejo de libertação que Ihe aflige. O eu-lírico representado na voz feminina é portador de características sóbrias que o faz um ser frágil e de fácil dominação. Notase que ela é retratada dessa forma como uma crítica à representação de até então, em que a mulher aparecia sob o poder do domínio colonial. A mulher, representada no poema, quer algo para se sentir bem, porém, percebe-se que ela sofre por conta da situação em que se encontra, pedindo para que sua situação melhore.

\section{O LUGAR DA MULHER NO PROCESSO COLONIAL AFRICANO}

O revisionismo crítico feminino tem analisado como se processava a dialética em relação ao papel que as mulheres exerciam no passado junto ao poder opressor. O processo colonial fomentou o uso de medidas que facilitaram, por 
tempos, o processo de subordinação da mulher frente ao poder masculino, o que viabilizava o conformismo e a posição para ela destinada (BOURDIEU, 2009).

Nesse sentido, no que diz respeito ao processo de colonização, as identidades angolanas passam a reclamar uma nova postura e posição social perante o poder dominador e frente à sociedade da qual faziam parte, uma vez que elas não se contentavam mais em ficar relegadas ao espaço privado, destituídas de outras ocupações.

Assim, na poesia de Tavares (2001, p.22):

SOMBRAS

(...)

Tristezas os olhos

De onde me olhas

Detrás de um tempo passado,

O tempo das promessas antigas

Teus olhos, amado,

São olhos de alguém

Que já morreu

E ainda não sabe

(...)

A voz que fala no poema, inferindo-se tratar de uma voz feminina, está encenada na ocupação de se encarregar de cuidados para com seu amado. Isso se vê na forma como o eu-lírico feminino apresenta seu interlocutor, o qual se encontra, possivelmente, devastado e "morto" pela guerra.

Dessa forma, vislumbra-se no poema em questão o comentário de Bonnici (2012, p.23), que diz: 
Desde a sua sistematização nos anos 1970, a crítica pós-colonial se preocupou com a preservação e documentação da literatura produzida pelos povos degradados como 'selvagens', primitivos e 'incultos' pelo imperialismo; com a recuperação das fontes alternativas da força cultural dos povos colonizados; com o reconhecimento das distorções produzidas pelo imperialismo e mantidas pelo sistema capitalista atual.

A crítica colonial se apodera dos registros ocorridos na Angola do passado, isto é, na forma como a mesma foi colonizada, com o intuito da reescrita e releitura dessas obras, a fim de proporcionar, ao colonizado, seu lugar de direito na história, no tocante à sua forma de representação. A releitura e reescritas, por sua vez, dizem respeito a como se deu o processo colonial e como as figuras femininas eram representadas nessa dialética, pois, percebeu-se que as mulheres quase não apareciam nos relatos, nem eram descritas nas obras literárias e, quando eram, elas eram retratadas de forma subordinada e subversiva pelo poder opressor (LEITE, 2013).

Ante o exposto, os homens, até pouco tempo atrás, detinham o controle sobre as formas do saber, sobretudo a literária. Desse modo, as mulheres que tinham conhecimento sobre a escrita eram poucas, pois essa era tarefa e função do homem (PERROT, 2007). 
Sobre o sujeito feminino e sua relação com o processo colonial, Tavares (2001, p.9) aponta que:

AMARGOS COMO FRUTOS
Amado por que voltas
com a morte nos olhos
e sem sandálias
como se um outro te habitasse
num tempo para além
do teu tempo
amado, onde perdeste tua língua de
metal
a dos sinais e do provérbio
com o meu nome inscrito
(...)

Observa-se que o sujeito que enuncia é marcado pela surpresa em ver seu amado, que volta da guerra destruído. 0 sujeito feminino desiludido vai ao encontro de seu amante, pois não consegue nem enxergar a língua do mesmo. Nesse contexto, a língua pode ser uma apologia à cultura. Vislumbra-se, pela voz do poema, que o dominado regressa da guerra sem expectativas, o que pode simbolizar que suas raízes e origens estão desaparecendo, supostamente, pelos povos das grandes potências imperialistas. A cultura do eulírico, vê-se, agora, em perigo, pois a cultura hegemônica tenta se sobressair sobre as outras formas de manifestações culturais, impondo seus valores. Diante desse fato, a mulher encontra-se duplamente colonizada: quando ela espera, passivamente, seu amado; e quando ela sofre junto com ele a morte de sua cultura. 


\section{CONSIDERAÇÕES FINAIS}

A poesia de Ana Paula Tavares é marcada por uma forte crítica aos padrões dominadores coloniais e masculinos, o que a classifica como defensora da mulher colonizada ao retratar os mais variados temas, explorado na representação feminina em sua poesia.

Confirma-se, pela análise do poema "Amargos como frutos", que a figura feminina é tratada de forma subalterna, tanto perante as potências imperialistas como ante o poder opressor, porque ela está sempre à espera dos cuidados e mandos do seu amado.

No caso da análise do poema "Tristes olhos", a mulher é representada de maneira pensativa e pessimista diante das consequências deixadas pelas potências imperialistas no território angolano. Isso a qualifica, por sua vez, como frágil e melancólica, pois se encontra diante de um destino mascarado pelo poder imperialista, cujo futuro são as marcas do período colonialista que manteve e governou as estruturas angolanas.

Entende-se, assim, que a representação da mulher, nas poesias em análise, é uma crítica que Ana Paula Tavares tece aos padrões tradicionais que avultavam Angola, no tocante à condição imposta às mulheres daquele território. Dessa 
forma, a escritora se posiciona de forma contrária à subversão e ao sexismo, tanto colonial como do poder masculino, quando estes se referiam à figura feminina. A escritora faz essa crítica através de seus poemas, representando a mulher de forma a se refletir sobre o lugar ocupado e retratado no período colonial pela personagem feminina.

Portanto, conclui-se que a mulher angolana volta-se para o processo colonial na medida em que o sente e reflete em seus comportamentos o jugo de um passado dolorido, cuja herança se manifesta na pós-modernidade, tentando ela cada vez mais se representar e mostrar o seu papel, que se opõe a um passado marcado pela hegemonia imperialista e masculina em território angolano, tendo como consequência última a mutação da tradição das estruturas arcaicas coloniais em Angola.

\section{REFERÊNCIAS}

BHABHA, Homi K. (1980). O local da cultura. 1a reimpressão. Belo Horizonte: Editora UFMG.

BONNICI, Thomas (2012). O pós-colonialismo e a literatura: estratégias de leitura. 2.ed. Maringá: Eduem.

BOURDIEU, Pierre (2009). A Dominação masculina. Maria Helena Kuhner (Trad.). 2.ed. Rio de Janeiro: Bertrand Brasil.

GARCÍA, Flávio; MATA, Inocência (Orgs.) (2016). Pós-colonial e póscolonialismo: propriedades e apropriações de sentido. Rio de Janeiro: Dialogarts Publicações. 
LEITE, Ana Mafalda (2013). Literaturas Africanas e Formulações PósColoniais. 2.ed. Lisboa: Colibri.

. Oralidades e Escritas nas Literaturas Africanas (2014). 2.ed. Lisboa: Colibri.

PERROT, Michelle (2007). Minha história das mulheres. São Paulo: Contexto.

TAVARES, Ana Paula (2001). Dizes-me coisas amargas como frutos. Lisboa: Caminho da Poesia.

Maria do Socorro Baptista Barbosa é Doutora pela UFSC 2005. A agência que fomenta a pesquisa é a CAPES. Dedica-se a estudar atuando principalmente nos seguintes temas: Literatura, Identidade Nacional, Literatura Canadense, Ensino, Leitura e Cultura, bem como Literatura e outras artes, em especial o Cinema. Email: socorrobaptista@uol.com

Francisco Brunno Carvalho Reis é Mestrando em Letras pela UESPI, no campus poeta Torquato Neto. A agência que fomenta a pesquisa é CAPES. Dedica-se a estudar memória e literaturas nas escritoras Luíza Amélia de Queiróz e em Lygia Fagundes Telles. Email: f.brunno20@hotmail.com 